\title{
UMA EXPERIÊNCIA DISCRETA: O MERCOSUL E AS OPINIÕES CONSULTIVAS
}

\author{
Ademar Pozzatti Junior* \\ Jânia Maria Lopes Saldanha**
}

\begin{abstract}
RESUMO: Para ser efetivo, um processo integracionista deve transcender aos aspectos econômicos para abarcar outras áreas do desenvolvimento estatal, pelas quais transitam o progresso integracionista, como educação, tecnologia e justiça. Conforme vão se desenvolvendo as estruturas dos blocos integracionistas e expressiva se torna a sua legislação, surge a necessidade que harmonização da interpretação desse direito regional. Para tanto, existem mecanismos processuais no Mercosul capazes de harmonizar a interpretação da lei. No Mercosul pesa contra a integração a não vinculação das decisões das opiniões consultivas.
\end{abstract}

PALAVRAS-CHAVES: Direito processual internacional. Mercosul.Opiniões consultivas.

ABSTRACT: In the way of being effective, an integration process may transcend the economic aspects to reach other State development areas, by which the integration progress transit, such as education, technology and justice. There are process mechanisms even in Mercosur as in European Union able to harmonize the interpretation of the Regional Law. In the Mercosur panel the integration has extended proceedings and non-connection from the decisions of the advisor opinions.

KEY WORDS: International process law. Mercosur. Advisor opinion.

*Acadêmico do $10^{\circ}$ semestre do Curso de Diteito da UFSM. E-mail: juniorpozzatti@ gmail.com

**Doutora em Direito. Professora do Curso de Direito e do Mestrado em Integração Latino-Americana da UFSM. Professora da Unisinos. E-mail: jania@smail.ufsm.br.

\section{INTRODUÇÃO}

Ao contrário do que acontece na União Européia, que excede largamente os limites intrínsecos às organizações internacionais clássicas, o Mercosul esposa estreitamente os contornos das organizações internacionais, aqui entendidas como sinônimo de organizações intergovernamentais.

Nesse sentido, é incontestável que no âmbito do Mercosul existem características que permitem reconhecer a existência de uma organização internacional clássica, já que foi criada por uma carta constitutiva, o Tratado de Assunção, de 1991, sendo esse bloco integracionista dotado de personalidade jurídica interna e internacional.

Com o desenvolvimento do Mercosul e o incremento das suas instituições, surgiram cada vez mais normas, que se consubstanciaram em um verdadeiro ordenamento jurídico mercosulino.

Em razão desse corpo de normas mercosulino cada vez mais se complexificar, surgiu a necessidade de se criarem mecanismos hábeis a unificar a aplicação e interpretação do mesmo perante os diversos Estados-partes que compõe o Mercosul. A 
resposta a essa necessidade é a possibilidade de se requerer opiniões consultivas, sendo essas o objeto de estudo desse estudo.

Para melhor estudar as opiniões consultivas, primeiramente far-se-á uma análise dos aspectos da harmonização da aplicação do direito regional no âmbito do Mercosul (1). Após, serão traçadas as linhas gerais que caracterizam as opiniões consultivas, assim como uma breve retrospectiva da mesma no ordenamento mercosulino (2). Em seguida será analisada minuciosamente a procedimentalidade das opiniões consultivas (3). Por fim, será traçado um panorama geral acerca da primeira opinião consultiva proferida pelo Tribunal Permanente de Revisão (TPR) no ano de 2007 (4).

\section{ASPECTOS DA HARMONIZAÇÃO DA APLICAÇÃO DO DIREITO REGIONAL NO MERCOSUL}

O Mercosul foi criado em 26 de março de 1991 pelo Tratado de Assunção, como conseqüência da vontade política da Argentina, Brasil, Paraguai e Uruguai de instituir um mercado comum, especialmente para satisfazer interesses de ordem econômica. Tal bloco é dotado de personalidade jurídica de direito internacional público, sendo a sua estrutura institucional baseada na intergovernamentalidade, conforme disposição expressa do artigo 34 do Protocolo de Ouro Preto, de 1994.

Caracteriza as instituições jurídicas intergovernamentais o fato de os Estadospartes do Mercosul preservarem as suas autonomias na inteireza, diferentemente do que acontece na União Européia, construída sobre o paradigma da supranacionalidade. No Mercosul, os Estados-partes mantêm a mesma liberdade de ação e decisão que tinham antes de pertencer ao bloco ${ }^{1}$. Assim, a intergovernamentalidade se caracteriza pela prevalência das vontades individuais dos Estados-partes, a quem não é imposta qualquer diretiva pela estrutura integracionista ${ }^{2}$.

Mesmo sem ter aquelas características vanguardistas da nobre dama européia, o jovem Mercosul conseguiu desenvolver significadamente as suas estruturas institucionais assim como a sua normativa própria. Hoje é inolvidável que existe no âmbito do Mercosul um ordenamento jurídico autônomo complexo, originário das estruturas integracionistas, já recepcionadas em grande parte pelos seus Estados-partes.

\footnotetext{
${ }^{1}$ VENTURA, Deisy. As assimetrias entre o Mercosul e a União Européia: os desafios de uma associação inter-regional. Barueri: Manole, 2003. Para a autora "as grandes linhas do direito comunitário não encontram nenhum eco nos contornos jurídicos do Mercosul. Em primeiro lu gar, o Mercosul adota uma estrutura institucional visivelmente minimalista. Em segundo lugar, o bloco não é dotado de uma ordem jurídica autônoma e constitui assim um fenômeno de direito internacional público clássico". p. 12.

${ }^{2}$ SALDANHA, Jânia Maria Lopes. Cooperação jurisdicional. Reenvio Prejudicial: um mecanismo de direito processual a serviço do direito comunitário: perspectivas para a sua adoção no Mercosul. Porto Alegre: Livraria do Advogado, 2001, p. 113.
} 
Assim como acontece na União Européia, são as jurisdições nacionais dos Estados-partes as responsáveis pela aplicação no caso concreto do direito proveniente do Mercosul. Deve-se acentuar que os juízes dos diferentes sistemas jurídicos nacionais carregam para a aplicação do direito mercosulino, ao caso concreto, as suas experiências na aplicação dos ordenamentos jurídicos nacionais.

Desse quadro traçado surgiu a necessidade de se implantar no âmbito do Mercosul um mecanismo processual hábil a harmonizar a aplicação do direito mercosulino nos diferentes Estados-partes que compõe o dito bloco. Dessa harmonização da interpretação e aplicação do direito mercosulino depende em grande monta o sucesso do Mercosul.

Já existe no âmbito do Mercosul órgão com competência para se pronunciar sobre a aplicação e interpretação uniforme do conjunto normativo proveniente das instituições mercosulinas. O mecanismo utilizado são as opiniões consultivas, e o órgão competente para decidir acerca das mesmas é o Tribunal Permanente de Revisão do Mercosul, doravante TPR.

\section{AS OPINIÕES CONSULTIVAS NA NORMATIVA DO MERCOSUL}

Já no tratado constitutivo do Mercosul havia a preocupação de que as diferentes ordens jurídicas de cada um dos seus Estados-partes poderiam comprometer o desenvolvimento do processo integracionista se não fossem harmonizadas de forma efetiva.

No entanto, foi somente onze anos depois do surgimento do Mercado Comum do Sul, que o Protocolo de Olivos para a solução de controvérsias no âmbito do Mercosul, de 18/02/2002, dispôs, pela primeira vez, no seu capítulo III, acerca das opiniões consultivas.

Entretanto, o Protocolo de Olivos não trouxe significativo avanço no que se refere à harmonização da aplicação do direito regional no âmbito do Mercosul. Este trouxe um único dispositivo, o artigo $2^{\circ}$, sobre o regime de solicitação das opiniões consultivas, segundo o qual caberia ao Conselho do Mercado Comum estabelecer mecanismos relativos à solicitação de opiniões consultivas ao TPR e o mesmo Conselho definiria o alcance e os procedimentos das mesmas.

De mais significativo, o Protocolo de Olivos apenas determinou que o TPR é o órgão responsável pela harmonização da aplicação do direito regional. 
Note-se que até o surgimento da regulamentação acerca dos procedimentos das opiniões consultivas, as eventuais controvérsias que surgiram entre os Estados-partes do Mercosul em decorrência da aplicação, interpretação ou descumprimento das disposições contidas nos diversos marcos regulatórios foram resolvidas mediante negociações diplomáticas diretas ${ }^{3}$.

Se mediante tais negociações diretas entre os corpos diplomáticos de cada um dos diversos Estados-partes do Mercosul não se alcançasse um acordo ou se a controvérsia só fosse solucionada parcialmente, eram aplicados os procedimentos previstos no Sistema de Solução de Controvérsias vigentes entre os Estados-partes do Tratado de Assunção, primeiramente dispostos no Protocolo de Brasília e depois no Protocolo de Olivos.

Foi somente com a prolação da Decisão no 37 de 2003 do Conselho do Mercado Comum, responsável pela regulamentação do Protocolo de Olivos para a solução de controvérsias no Mercosul, que se estruturou pela primeira vez no âmbito do bloco do cone sul o mecanismo hábil a harmonizar a interpretação e aplicação do direito mercosulino.

Dispõe a Decisão n ${ }^{\circ} 37 / 03$ do CMC, no seu artigo $2^{\circ}$ sobre a legitimação para solicitar opiniões consultivas. São três as hipóteses de competência para solicitação de opiniões consultivas ao $\mathrm{TPR}^{4}$ :

a) todos os Estados-partes do Mercosul, atuando conjuntamente;

b) qualquer órgão com capacidade decisória do Mercosul; e

c) os Tribunais Superiores dos Estados-partes com jurisdição nacional, nas condições que se estabeleçam para cada caso.

Quanto a esta terceira competência para solicitar opiniões consultivas, consideram-se especificamente os seguintes tribunais de cada um dos Estados-partes:

- República Argentina: Corte Suprema de Justicia de la Nación;

- República Federativa do Brasil, Supremo Tribunal Federal;

- República do Paraguai, Corte Suprema de Justicia; e

- República Oriental do Uruguai, Suprema Corte de Justicia y Tribunal de lo Contencioso Administrativo.

Diferentemente do que acontece no âmbito da União Européia, onde qualquer juiz nacional, de qualquer instância, pode solicitar ao tribunal comunitário auxílio

\footnotetext{
${ }^{3}$ Para maiores esclarecimentos, ver: Jânia Maria Lopes Saldanha, Op. cit.

${ }^{4}$ Artigo $2^{\circ}$ da Decisão $n^{\circ} 37 / 03$ do CMC: "Poderão solicitar opiniões consultivas ao TPR todos os Estados Partes do MERCOSUL, atuando conjuntamente, os órgãos com capacidade decisória do MERCOSUL e os Tribunais Superiores dos Estados Partes com jurisdição nacional, nas condições que se estabeleçam para cada caso".
} 
acerca da interpretação ou aplicação da normativa comunitária, no Mercosul há uma concentração de competência nas supremas cortes de cada país para a solicitação de opiniões consultivas.

Dessa forma, no Mercosul, o juiz nacional de primeira instância, responsável pela aplicação do direito nacional e do direito regional em primeiro grau de jurisdição, quando se deparar com uma dúvida acerca da interpretação da normativa regional deverá enviar a solicitação de opinião consultiva para a Suprema Corte de Justiça do seu país, que por sua vez, enviará para o TPR.

Esse intermédio das supremas cortes de cada país acarretará morosidade ao procedimento prejudicial, dificultando o efetivo acesso à justiça daquele jurisdicionado que depende desta questão prévia para ter resolvida a sua questão jurídica.

Ademais, essa mediação das supremas cortes também onera a tramitação das opiniões consultivas, que poderia ser muito mais ágil com a transmissão direta da questão prejudicial pelo juiz nacional ao TPR, como acontece na tramitação de um reenvio prejudicial na União Européia.

Quando todos os Estados-partes do Mercosul, agindo conjuntamente, solicitarem uma opinião consultiva ao TPR, a mesma poderá versar sobre qualquer questão jurídica compreendida no Tratado de Assunção, no Protocolo de Ouro Preto, nos protocolos e acordos celebrados no marco desses tratados, nas decisões do Conselho do Mercado Comum, nas resoluções do Grupo do Mercado Comum e nas diretrizes da Comissão de Comércio do Mercosul.

Ainda quanto à solicitação conjunta, o Estado ou os Estados-partes que desejarem pedir uma opinião consultiva ao TPR apresentarão um projeto de solicitação aos demais Estados-partes com o objetivo de conseguirem um consenso acerca do seu objeto e conteúdo. Alcançado o consenso, será preparado o texto da solicitação da opinião consultiva, que será apresentada ao TPR através da secretaria deste tribunal. Isto está previsto no artigo $3^{\circ}$ da Decisão $n^{\circ} 37 / 03$ do CMC.

As opiniões consultivas também podem ser solicitadas por órgãos do Mercosul, quais sejam: o Conselho do Mercado Comum (CMC), o Grupo do Mercado Comum (GMC) e a Comissão de Comércio do Mercosul (CCM).

Da mesma maneira que ocorre quando a solicitação de opinião consultiva emanar conjuntamente dos Estados-partes do Mercosul, quando emanar dos órgãos da integração legitimados, poderão versar apenas sobre questões jurídicas compreendidas nos marcos regulatórios anteriormente referidos. 
Por fim, no caso de as opiniões consultivas emanarem de uma das supremas cortes estatais retro elencadas, elas deverão referir-se exclusivamente à interpretação jurídica da normativa mercosulina mencionada já referida anteriormente, porém, somente quando se vincularem com causas que estejam em tramitação nos órgãos judiciários do Estado-parte suscitante, conforme disposição do $\operatorname{artigo} 4^{\circ}$ da decisão 37/03 do CMC.

\section{O PROCEDIMENTO PARA A SOLICITAÇÃO E TRAMITAÇÃO DAS OPINIÕES CONSULTIVAS}

O procedimento para o requerimento de opiniões consultivas ao TPR está previsto em duas decisões do CMC: Decisão 37/2003 e Decisão 02/2007.

Quanto ao procedimento para a solicitação de uma opinião consultiva ao TPR, este segue diretivas diferentes dependendo de quem a solicita. Quando se tratar de pedido dos Estados-partes conjuntamente ou de algum órgão do Mercosul, não existe até o momento a regulamentação.

Por outro lado, quando se tratar de pedido dos tribunais superiores de justiça de cada um dos Estados-partes, a regulamentação está prevista na Decisão nº 02/2007 do CMC. É desse procedimento que se tratará a seguir, conforme disposição do artigo $1^{\circ}$ da referida decisão.

Cada Suprema Corte de Justiça dos Estados-partes, no entanto, deverá estabelecer regras internas de procedimento para a solicitação de opiniões consultivas, verificando a adequação processual da solicitação.

Essa margem nacional ${ }^{5}$ existe porque, assim como no reenvio prejudicial europeu, a opinião consultiva é um procedimento composto por várias etapas. Primeiramente ocorre uma tramitação interna, onde o juiz nacional de primeiro grau envia à respectiva Suprema Corte de Justiça o requerimento de uma opinião consultiva. Em segundo lugar, a Suprema Corte de Justiça do Estado-parte envia a solicitação de uma opinião consultiva à secretaria do TPR. Em terceiro lugar, a secretaria do TPR devolve a decisão da opinião consultiva para a Suprema Corte de Justiça do país suscitante que, por fim, devolverá a decisão da opinião consultiva ao juiz suscitante.

Note-se que as Supremas Cortes de Justiça nacionais indicados no $\operatorname{artigo} 2^{\circ}$ da Decisão no $37 / 03$ do CMC poderão delegar a sua competência para suscitar as opiniões

\footnotetext{
${ }^{5}$ Aqui, a expressão margem nacional remonta à Mireille Delmas-Marty, pois os procedimentos internos de cada país acerca da solicitação das opiniões consultivas não é pré-determinado pela normativa regional, e sim depende de diretrizes internas.
} 
consultivas, desde que o órgão judiciário delegado também preencha a condição de tribunal superior com jurisdição nacional. $\mathrm{Na}$ hipótese de a solicitação proceder de órgão judiciário delegado, o recebimento do pedido pressupõe comunicação prévia, de forma formal, do termo de delegação à Secretaria do TPR ${ }^{6}$.

Independentemente de quem emane a solicitação de uma opinião consultiva, a solicitação deverá ser feita sempre por escrito, formulando em termos precisos a questão a respeito da qual se realiza a consulta e as razões que a motivam, indicando as normas do Mercosul vinculadas à questão objeto da opinião consultiva. Da mesma forma, o requerimento de uma opinião consultiva deverá ser acompanhado por toda a documentação que possa ser necessária para a melhor elucidação da mesma ${ }^{7}$.

A Suprema Corte de Justiça de um Estado-parte, quando solicitar uma opinião consultiva, deverá apresentá-la, logicamente, por escrito, e, de acordo com o Artigo $4^{\circ}$ da decisão CMC No 02/07, conterá os seguintes elementos:

a) exposição dos fatos e do objeto da solicitação;

b) descrição das razões que motivaram a solicitação; e

c) indicação precisa da normativa Mercosul que estiver envolvida na questão objeto da opinião consultiva.

A solicitação da opinião consultiva emanada de uma Suprema Corte poderá estar acompanhada de considerações formuladas pelas partes em litígio e pelo Ministério Público do respectivo Estado acerca da questão objeto da consulta e de qualquer documentação que possa contribuir para sua instrução

Por sua vez, o TPR poderá solicitar ao tribunal suscitante os esclarecimentos e a documentação que entenda necessários ao exercício de sua competência, de acordo com o artigo $8^{\circ}$ da Decisão no 37/03 do CMC.

Conforme disposição do artigo $4^{\circ}$ da decisão 37/03 do CMC, a decisão 02/2007, também no seu artigo $4^{\text {o }}$ estabelece que as opiniões consultivas solicitadas por um dos tribunais superiores elencados no artigo $2^{\mathrm{a}}$ deverão estar necessariamente vinculadas a causas em trâmite no poder judiciário ou a instâncias jurisdicionais contenciosas ou administrativas do Estado-parte solicitante.

Os tribunais superiores dos Estados-partes encaminharão as solicitações de opiniões consultivas ao TPR por intermédio de sua secretaria, sendo que também

\footnotetext{
${ }^{6}$ Ver artigo 03 da decisão n ${ }^{\circ}$ 02/07 do CMC

${ }^{7}$ Ver artigo 05 da decisão no $37 / 03$ do CMC
} 
enviarão cópia para a secretaria do Mercosul e para os demais tribunais superiores dos demais Estados-partes ${ }^{8}$.

O artigo $7^{\circ}$ da decisão 37/03 do CMC traz hipóteses em que o TPR denegará a solicitação da opinião consultiva: quando a solicitação não proceder de um dos tribunais superiores designados pelos Estados-partes; quando o pedido não estiver formulado de acordo com o disposto no artigo $4^{\circ}$ do mesmo Regulamento e, por fim, quando a questão em causa for objeto de outro procedimento de solução de controvérsias em curso.

Acolhida a solicitação de opinião consultiva, o presidente do TPR coordenará com os demais integrantes do mesmo a designação do árbitro responsável que se encarregará da coordenação da resposta.

Os coordenadores nacionais do GMC poderão enviar, em um prazo de quinze dias contados a partir da notificação de recebimento de uma solicitação de opinião consultiva, para fins informativos, suas eventuais considerações sobre o tema objeto da solicitação de opinião consultiva.

As opiniões consultivas emitidas pelo TPR serão enviadas diretamente ao tribunal superior solicitante e notificadas a todos os Estados-partes, com cópia à secretaria do Mercosul e aos tribunais superiores dos demais Estados-partes.

Dispõe o artigo $11^{\circ}$ da decisão 02/07 do CMC que os gastos derivados da emissão de opiniões consultivas solicitadas por qualquer dos tribunais superiores dos Estados-partes, tais como os honorários, os gastos de traslado, diárias dos integrantes do TPR e os demais gastos que possam derivar de sua tramitação, serão custeados pelo Estado-parte ao qual pertença o tribunal peticionário.

Para emitir opiniões consultivas, o Tribunal Permanente de Revisão será integrado por todos os seus 05 (cinco) membros ${ }^{9}$. Recebida a solicitação de uma opinião consultiva, o secretário do Tribunal Permanente de Revisão imediatamente comunicará tal solicitação aos membros do TPR.

Os membros do Tribunal Permanente de Revisão decidirão, de comum acordo, qual deles será encarregado da tarefa de coordenar a redação da resposta à consulta. Caso não haja acordo a respeito, o presidente do TPR designará, por sorteio, o árbitro que desempenhará essa tarefa ${ }^{10}$.

\footnotetext{
${ }^{8}$ Artigo 05 da decisão n ${ }^{\circ}$ 02/07 do CMC.

${ }^{9}$ A constituição do Tribunal Permanente de Revisão do Mercosul está prevista no artigo 18 do Protocolo de Olivos para a solução de controvérsias do Mercosul.

${ }^{10}$ Artigo $6^{\circ}$ da decisão n ${ }^{\circ}$ 37/03 do CMC.
} 
Note-se que caberá ao TPR criar as suas próprias regras de procedimento que correspondam à tramitação das opiniões consultivas dentro do Tribunal.

Ademais, quanto ao prazo para a emissão de opiniões consultivas, deve-se observar o disposto no artigo $7^{\circ}$ da Decisão $n^{\circ} 37 / 03$ do CMC. O TPR se pronunciará por escrito dentro do prazo de quarenta e cinco dias contados a partir da recepção da solicitação da opinião consultiva.

Para fins de não tornar morosa a emissão das opiniões consultivas, o TPR funcionará mediante intercâmbio de comunicações à distância, tais como fax e correio eletrônico. Caso o TPR estime necessário reunir-se para uma melhor análise da questão suscitada, assim será feito.

O TPR poderá solicitar aos peticionantes de opiniões consultivas os esclarecimentos e a documentação que estime pertinente. O diligenciamento dos mencionados trâmites não suspenderá, em regra, o prazo de 45 dias para a prolatação da decisão, a menos que o TPR o considere necessário.

Note-se que caberá aos próprios tribunais superiores dos Estados-partes colaborar com o TPR para a rápida solução da questão proposta. Os mecanismos de harmonização da aplicação do direito regional, dos quais a opinião consultiva é o modelo mercosulino, são uma forma de cooperação vertical entre as jurisdições nacionais e regionais, cabendo a ambas não medir esforços para o sucesso do processo integracionista.

É, portanto, no âmbito da margem nacional dos Estados-partes, da qual fala Mireille Delmas-Marty, que se pode facilitar a tramitação dos pedidos de consulta, a fim de dinamizar os procedimentos internos pelos quais os juízes de primeira instância fazem chegar o requerimento de decisão prejudicial à suprema sorte do seu país.

As opiniões consultivas serão fundamentadas pelo TPR conforme disposição do artigo 34 do Protocolo de Olivos, ou seja, decidirá a controvérsia com base no Tratado de Assunção, no Protocolo de Ouro Preto, nos protocolos e acordos celebrados no marco desses tratados, nas Decisões do CMC, nas Resoluções do GMC e nas Diretrizes da CCM, bem como nos princípios e disposições de Direito Internacional aplicáveis à matéria ${ }^{11}$.

Ademais, para fins de organização da decisão de uma opinião consultiva, prevê o artigo $9^{\circ}$ da Decisão n 37/03 do CMC que a fundamentação do Tribunal Permanente de Revisão deverá conter uma relação das questões submetidas à consulta, um resumo 
dos esclarecimentos dos solicitantes, se o Tribunal os tiver pedido e o parecer do TPR com a opinião da maioria e as opiniões em dissidência, se for o caso

Ainda há disposição expressa do Conselho do Mercado Comum que as decisões das opiniões consultivas serão fundamentadas e assinadas por todos os árbitros intervenientes.

Prevê o artigo $10^{\circ}$ Decisão n $37 / 03$ do CMC que o procedimento consultivo poderá ser finalizado de diversas maneiras, quais sejam:

a) a forma típica é a emissão da decisão da opinião consultiva, razão de existência de todo o procedimento que vem sendo analisado neste capítulo;

b) a comunicação ao peticionante de que a opinião consultiva não será emitida por alguma causa fundamentada, tal como a falta dos elementos necessários para o pronunciamento do TPR;

c) o início de um procedimento de solução de controvérsias sobre a mesma questão. Nesse caso, o procedimento consultivo deverá ser finalizado pelo TPR sem mais trâmites. Isto ocorre para que não hajam decisões díspares e também para que não acarrete tumulto de processos com o mesmo objeto pendentes de julgamento no TPR.

Quaisquer desses pronunciamentos do Tribunal Permanente de Revisão do Mercosul deverão ser notificadas ao peticionante assim como a todos os demais Estados-partes, através da Secretaria do TPR.

Importante é o dispositivo $11^{\circ}$ da Decisão $n^{\circ} 37 / 03$ do CMC ao afirmar que as opiniões consultivas emitidas pelo TPR não serão vinculantes nem obrigatórias.

Essa não vinculação significa que o órgão suscitante de uma opinião consultiva não está adstrito a decisão do TPR, diferentemente do que acontece com o reenvio prejudicial na União Européia. Nesse caso, a decisão do tribunal comunitário é lei no caso concreto, que não poderá deixar de ser aplicada pelo órgão jurisdicional suscitante. Na União Européia, a decisão de um reenvio prejudicial, diferentemente, é vinculante à decisão do caso concreto, incorrendo em grave descumprimento a sua não observância pelo juiz nacional.

No âmbito mercosulino, o mecanismo das opiniões consultivas é, na verdade, uma mera consulta do juízo nacional ou do órgão mercosulino acerca da correta aplicação da normativa regional. Como diz o próprio nome, uma consulta não tem qualquer comprometimento com a decisão a ser tomada pelo juiz nacional no caso concreto. Essa não obrigatoriedade da observância da decisão de uma opinião consultiva, no âmbito do Mercosul, é um reflexo do paradigma da 
intergovernamentalidade que caracteriza a experiência integracionista do sul. Portanto, esse mecanismo já nasce frágil, visto que não tem qualquer força vinculante.

O Mercosul perdeu a oportunidade de dar um significativo salto rumo a uma integração mais sólida, através da mitigação da intergovernabilidade que caracteriza o bloco e inserção de políticas que valorizassem a atuação da estrutura integracionista, no caso o Tribunal Permanente de Revisão.

Quando o TPR já tiver se manifestado acerca da interpretação de uma determinada matéria, não será necessário que o juízo nacional a suscite novamente para saber a posição do tribunal. Corrobora com este entendimento o fato de que todos os Estados-partes, assim com a secretaria do Mercosul, deverão ser devidamente cientificados de toda e qualquer decisão de opinião consultiva prolatada pelo TPR.

Como acontece com o reenvio prejudicial no âmbito da União Européia, podese entender que o órgão jurisdicional nacional poderá suscitar a interpretação de determinada matéria já decidida em alguns casos.

Nesse sentido, quanto ao reenvio prejudicial, as questões de interpretação que já foram resolvidas em casos análogos anteriores, não impediam que os juízes nacionais as suscitassem novamente, através de novo reenvio prejudicial em três hipóteses: quando o juiz nacional não estiver suficientemente esclarecido pela decisão tomada no outro reenvio prejudicial, quando a situação de fato ou de direito não for idêntica a anterior e, por fim, quando o juiz nacional desejar provocar uma evolução jurisprudencial $^{12}$.

Assim, não há porque não aplicar o mesmo raciocínio quando se tratar das opiniões consultivas, que poderão veicular questões já suscitadas e resolvidas anteriormente, nos mesmos casos elencados acima pela douta doutrinadora.

Por fim, conforme disposição expressa do artigo 13 da Decisão no 37/03 do CMC, as opiniões consultivas emitidas pelo Tribunal Permanente de Revisão serão publicadas no Boletim Oficial do Mercosul. Essa publicidade, não há dúvida, corrobora para a formação de um pensamento próprio do TPR, a ser aplicado pelos juízes nacionais e órgãos regionais mercosulinos.

\section{A PRIMEIRA OPINIÃO CONSULTIVA DO MERCOSUL}

\footnotetext{
${ }^{12}$ Jânia Maria Lopes Saldanha. Op. cit., p. 78.
} 
Até o presente momento apenas uma opinião consultiva foi decidida pelo Tribunal Permanente de Revisão. Trata-se da Opinião Consultiva $\mathrm{n}^{\circ}$ 01/2007, publicada na capital do Paraguai, Assunção, sede do TPR, no dia 03 de abril de 2007.

A petição da primeira Opinião Consultiva foi apresentada pela juíza de Primeira Instância no Civil e Comercial do Primeiro Turno da jurisdição de Assunção, Paraguai, a magistrada Maria Angélica Calvo. A consulta ocorreu no âmbito no expediente denominado: "Norte S.A. Imp. Exp. c/ Laboratórios Northia Sociedade Anônima, Comercial, Industrial, Financeira, Imobiliária e Agropecuária s/Indenização de Danos e Prejuizos e Lucro Cessante”. A tramitação da referida petição passou pela via da Corte Suprema de Justiça da República do Paraguai, tendo sido recebida pelo Tribunal Permanente de Revisão em 21 de dezembro de 2006.

No julgamento, o TPR estava integrado pelo Dr. Nicolás Eduardo Becerra na qualidade de Presidente TPR, o Dr. João Grandino Rodas, o Dr. Wilfrido Fernández de Brix, o Dr. Ricardo Olivera Garcia e o Dr. José Antonio Moreno Ruffinelli. Por consenso foi designado Coordenador da redação da resposta à consulta o Dr. Wilfrido Fernández de Brix, conforme disposição do artigo $6^{\circ}$ do Protocolo de Olivos.

Trata-se de opinião consultiva surgida no âmbito de um litígio judicial entre a empresa argentina Laboratórios Northia Sociedade Anônima, Comercial, Industrial, Financeira, Imobiliária e Agropecuária e a empresa paraguaia Norte S.A. Imp. Exp.

A empresa paraguaia Norte S.A. pleiteia indenização de danos e prejuízos e lucro cessante junto a jurisdição de Assunção, com base na Lei nacional paraguaia $\mathrm{n}^{\circ}$ $194 / 93$

A empresa argentina Laboratórios Northia opôs exceção de incompetência de foro argumentando a prevalência do artigo $4^{\circ}$ do Protocolo de Buenos Aires sobre Jurisdição Internacional em Matéria Contratual em relação a lei nacional paraguaia $\mathrm{n}^{\mathbf{o}}$ 194/93. Ademais, alegou que o foro eleito pelas partes era o dos Tribunais Ordinários da Cidade de Buenos Aires, conforme cláusula 22 do contrato inter partes, sustentando a primazia do tratado do Mercosul sobre a lei nacional paraguaia.

Em sede de resposta à exceção, a empresa paraguaia questiona a validade da escolha de foro feita pelas partes, já que a norma paraguaia sobre o tema não permite esta situação.

A parte argentina argumenta que vigora o princípio da supremacia da normativa Mercosul sobre a lei nacional paraguaia, devendo a escolha do foro ser 
respeitada. Defende o Protocolo de Buenos Aires, argumentando valer a eleição do foro, no caso, Buenos Aires. Alega que não há abuso na eleição do foro.

Por fim, a empresa paraguaia invoca o Protocolo de Santa Maria sobre as Relações de Consumo, que exclui os contratos com consumidores da possibilidade de eleição de foro. Ainda em sede de resposta à exceção, a empresa paraguaia sugeriu que fosse suscitada uma opinião consultiva.

Note-se que essa primeira opinião consultiva é proveniente de uma sugestão da empresa paraguaia, para fins de averiguar a aplicabilidade da norma comunitária invocada. Claro que a decisão acerca da pertinência da consulta sobre tal questão ficou a cargo da juíza competente, que acatou a sugestão da parte.

A questão prejudicial apresentada pela magistrada paraguaia versa sobre qual seria a jurisdição competente para a solução da controvérsia em questão, a argentina, Buenos Aires, ou a paraguaia, Assunção.

O litígio suscita um conflito entre o Protocolo de Buenos Aires sobre jurisdição em matéria contratual e a lei paraguaia n 194/93. O Protocolo de Buenos Aires, em seu capítulo I, permite que as partes utilizem-se do princípio da autonomia da vontade para eleger o foro competente para demandas contratuais, sempre que as empresas estejam localizadas em diferentes países do Mercosul. $\mathrm{O}$ art. $2^{\circ}$ do referido Protocolo, no entanto, exclui do âmbito de aplicação do protocolo alguns tipos de contrato, entre eles os de compra e venda ao consumidor, transporte e seguro.

Razão pela qual a empresa paraguaia entende não ter validade o foro eleito. $\mathrm{Ou}$ seja, entende que se trata de um caso envolvendo o direito do consumidor, estando excluído do âmbito do Protocolo de Buenos Aires.

Inicialmente o relator, Dr. Wilfrido Fernández de Brix, define uma opinião consultiva como sendo uma consulta prejudicial, sem caráter obrigatório, que não decide casos concretos, mas apenas dá resposta a perguntas de caráter jurídico.

No entanto, não há como deixar de referir a insatisfação do relator com a não vinculação da decisão prejudicial. Diz ser lamentável a não obrigatoriedade das decisões de opiniões consultivas, aduzindo não haver qualquer equivalente no direito comparado, instando mudanças dessa ordem para um melhor aproveitamento do Tribunal Permanente de Revisão.

Após a exposição dos votos de cada um dos juízes componentes, o TPR decidiu que: 
a) as opiniões consultivas peticionadas pelos órgãos judiciais nacionais devem ser consideradas como meras interpretações prejudiciais consultivas, não vinculantes. Nas mesmas, cabe ao TPR interpretar o direito de integração do Mercosul, sendo a aplicação de tal interpretação de exclusiva competência dos órgãos jurisdicionais nacionais;

b) as normas do Mercosul internalizadas prevalecem sobre as normas do direito interno dos Estados-partes. O Protocolo de Buenos Aires se aplica nos países que o internalizaram, ficando a cargo do juiz nacional a avaliação dos acordos abusivos subscritos pelas partes;

c) o Protocolo de Santa Maia sobre relações de consumo não tem aplicabilidade no caso concreto suscitado. Dois são os motivos: não estar vigente por não ter sido internalizado por nenhum Estado-parte e por referir-se a relação de consumo, excluída expressamente do Protocolo de Buenos Aires.

Desta decisão, percebe-se que mesmo que nem todas as Constituições dos Estados-partes do Mercosul expressem a prevalência dos tratados internacionais sobre as leis nacionais, o Direito do Mercosul possui caráter de norma comunitária, ou seja, sua prevalência sobre as leis nacionais é necessária para que se alcance o objetivo da integração regional.

A decisão concluiu pela prevalência da normativa mercosulina sobre as normas de direito interno dos Estados-partes do bloco e, portanto, a prevalência do Protocolo de Buenos Aires sobre a lei paraguaia n 194/93, no caso em questão.

Decidiu o TPR que a justiça paraguaia é a competente para decidir a controvérsia. Ao mesmo tempo, entendeu que cabe ao "juiz nacional" verificar o abuso suscitado. As custas, por fim, ficaram a cargo da República do Paraguai.

Teve voto vencido o Dr. Wilfrido Fernández de Brix, uma vez que o TPR decidiu que a referida decisão não vincula o juízo nacional suscitante, o qual poderá, portanto, decidir diferentemente do TPR.

Portanto, as normas do Mercosul prevalecem às dos Estados-partes somente quando internalizadas. O Protocolo de Buenos Aires é aplicável no caso, já que internalizado pelos Estados conflitantes.

O TPR entendeu necessário recomendar ao Conselho do Mercado Comum a revisão das Resoluções n ${ }^{\circ}$ 02/07 do CMC e nº 02/07 do GMC, quanto ao pagamento das custas, por entender que uma opinião consultiva não afeta um só país, sendo um mecanismo de cooperação que enriquece o processo de integração. Assim, sendo 
opinião consultiva ferramenta de construção do direito da integração, todos os países são beneficiários do mesmo, e, conseqüentemente, devem conjuntamente sustentar os gastos e honorários correspondentes.

\section{CONCLUSÃO}

Do que foi exposto, percebeu-se a importância de haver um mecanismo hábil à harmonização da aplicação do direito regional para dotar de coerência o sistema jurídico regional.

Em um processo de integração de natureza intergovernamental, como o Mercosul, o interesse predominante é o resultado da vontade individual de cada Estadoparte. Não há uma significativa estrutura institucional, e as normas jurídicas devem ser submetidas aos processos de internalização previstos nos textos legislativos de cada País, em geral, suas Constituições Federais. Não se fala em aplicabilidade imediata das normas emanadas das instituições e tampouco em primazia frente aos ordenamentos jurídicos nacionais.

Dessa maneira, as opiniões consultivas seguem a lógica da intergovernabilidade, já que não vinculam as decisões dos juízos nacionais no caso concreto.

Importante salientar que a primeira solicitação de opinião consultiva, proveniente da Corte Suprema de Justiça da República do Paraguai, julgada em 2007 não trouxe qualquer avanço procedimental, assim como se mostrou confusa, não investindo na praticidade.

Como muito bem referiu o relator da primeira opinião consultiva, Dr. Wilfrido Fernández de Brix, o Mercosul perde muito em termos de harmonização da aplicação do direito regional por não dotar de obrigatoriedade as decisões do TPR em sede de uma opinião consultiva.

Grande é o abismo que separa as estruturas mercosulinas e européias acerca da harmonização da aplicação do direito regional. No entanto, nem tudo está perdido, havendo motivos para continuar confiante no processo integracionista do sul. Os protocolos mercosulinos são um avanço em nada desprezível à harmonização da aplicação do direito regional.

\section{REFERÊNCIAS BIBLIOGRÁFICAS}


DELMAS-MARTY, Mireille. Três desafios para um direito mundial. Rio de Janeiro: Editora Lúmen Júris, 2003.

SALDANHA, Jânia Maria Lopes. Cooperação jurisdicional. Reenvio Prejudicial: um mecanismo de direito processual a serviço do direito comunitário: perspectivas para a sua adoção no Mercosul. Porto Alegre: Livraria do Advogado, 2001.

STRENGER, Irineu. Direito Processual Internacional. São Paulo: LTR, 2003.

VENTURA, Deisy. A ordem jurídica do MERCOSUL. Porto Alegre: Livraria do Advogado, 1996.

As assimetrias entre o Mercosul e a União Européia: os desafios de uma associação

inter-regional.

Barueri:

Manole,

2003. 
